\title{
Characterization of Patients with Pulmonary Arterial Hypertension: Data from the Polish Registry of Pulmonary Hypertension (BNP-PL)
}

\author{
Grzegorz Kopeć 1,*D, Marcin Kurzyna ${ }^{2}$ (D), Ewa Mroczek ${ }^{3}$, tukasz Chrzanowski ${ }^{4}$, \\ Tatiana Mularek-Kubzdela ${ }^{5}$, Ilona Skoczylas ${ }^{6}$, Beata Kuśmierczyk ${ }^{7}$, Piotr Pruszczyk ${ }^{8}$, \\ Piotr Błaszczak ${ }^{9}$, Ewa Lewicka ${ }^{10}$, Danuta Karasek ${ }^{11}$, Katarzyna Mizia-Stec ${ }^{12}$, \\ Michał Tomaszewski ${ }^{13}$, Wojciech Jacheć ${ }^{14}$, Katarzyna Ptaszyńska-Kopczyńska ${ }^{15}$, \\ Małgorzata Peregud-Pogorzelska ${ }^{16}$, Anna Doboszyńska ${ }^{17}$, Agnieszka Pawlak ${ }^{18}$ (D), \\ Zbigniew Gąsior ${ }^{19}$, Wiesława Zabłocka ${ }^{20}$, Robert Ryczek ${ }^{21}$, Katarzyna Widejko-Pietkiewicz ${ }^{22}$, \\ Marcin Waligóra ${ }^{1}$, Szymon Darocha ${ }^{2}$, Michał Furdal ${ }^{3}$, Michał Ciurzyński ${ }^{8}$, \\ Jarosław D. Kasprzak ${ }^{4}$ (D), Marek Grabka ${ }^{12}$, Karol Kamiński ${ }^{23}{ }^{\mathbb{D}}$, Piotr Hoffman ${ }^{7}$ (D), \\ Piotr Podolec ${ }^{1}$ and Adam Torbicki ${ }^{2}$ DD
}

1 Department of Cardiac and Vascular Diseases, Jagiellonian University Medical College, John Paul II Hospital in Krakow, Ul. Prądnicka 80, 31-202 Krakow, Poland; marcin.waligoora@gmail.com (M.W.); ppodolec@interia.pl (P.P)

2 Department of Pulmonary Hypertension, Thromboembolic Diseases and Cardiology, Centre of Postgraduate Medical Education, 05-400 Otwock, Poland; marcin.kurzyna@ecz-otwock.pl (M.K.);

szymondarocha@gmail.com (S.D.); adam.torbicki@ecz-otwock.pl (A.T.)

3 Department of Cardiology Provincial Specialist Hospital Research and Development Center, 51-124 Wrocław, Poland; mroczeke@wp.pl (E.M.); m.furdal@gmail.com (M.F.)

4 Cardiology Department, Medical University of Lodz, 91-347 Lodz, Poland; chrzanowski@ptkardio.pl (Ł.C.); kasprzak@ptkardio.pl (J.D.K.)

5 Department of Cardiology, Poznan University of Medical Sciences, 61-701 Poznan, Poland; tatianamularek@wp.pl

6 3rd Department of Cardiology, Faculty of Medical Sciences in Zabrze, Medical University of Silesia, 41-800 Katowice, Poland; iskoczylas@tlen.pl

7 Department of Congenital Heart Disease Institute of Cardiology, 04-628 Warsaw, Poland; bkusmier@gmail.com (B.K.); hoffman@ikard.pl (P.H.)

8 Department of Internal Medicine and Cardiology, Medical University of Warsaw, 02-005 Warsaw, Poland; piotr.pruszczyk@wum.edu.pl (P.P.); michal.ciurzynski@wum.edu.pl (M.C.)

9 Department of Cardiology, Cardinal Wyszynski Hospital, 20-718 Lublin, Poland; blaszcz12345@interia.pl

10 Department of Cardiology and Electrotherapy Medical University of Gdansk, 80-211 Gdansk, Poland; elew@gumed.edu.pl

11 2nd Department of Cardiology, Faculty of Health Sciences, Collegium Medicum, Nicolaus Copernicus University, 85-168 Bydgoszcz, Poland; danuta.karasek@op.pl

12 I Katedra i Klinika Kardiologii, Wydział Lekarski w Katowicach, Śląski Uniwersytety Medyczny w Katowicach, 40-635 Katowice, Poland; kmiziastec@gmail.com (K.M.-S.); marekgrabka@interia.pl (M.G.)

13 Department of Cardiology, Medical University of Lublin, 20-090 Lublin, Poland; mdtomaszewski@wp.pl

14 2nd Department of Cardiology, School of Medicine with Dentistry Division in Zabrze, Medical University of Silesia in Katowice, 41-800 Zabrze, Poland; wjachec@interia.pl

15 Department of Cardiology, Medical University of Bialystok, 15-276 Bialystok, Poland; kasia.ptaszynska@op.pl

16 Department of Cardiology, Pomeranian Medical University, Szczecin, 70-111 Szczecin, Poland; m1peregud@gmail.com

17 Pulmonary Department, University of Warmia and Mazury, 10-357 Olsztyn, Poland; anna.doboszynska@wp.pl

18 Department of Invasive Cardiology, Polish Academy of Sciences, Mossakowski Medical Research Centre, Central Clinical Hospital of the Ministry of Interior, 02-507 Warsaw, Poland; a.pawlak1@wp.pl

19 Department of Cardiology, School of Health Sciences, Medical University of Cardiology in Katowice, 40-635 Katowice, Poland; zbgasiar@gmail.com 
20 Oddział Kardiologii i Kardiologii Inwazyjnej, Oddział Intensywnego Nadzoru Kardiologicznego, Samodzielny Publiczny Wojewódzki Szpital Zespolony w Szczecinie, 71-455 Szczecin, Poland; wieslawa.zablocka@wp.pl

21 Department of Cardiology and Internal Medicine, Military Institute of Medicine in Warsaw, 04-141 Warsaw, Poland; raryczek@gmail.com

22 Department of Cardiology, Copper Health Center, 59-300 Lubin, Poland; kwidejko@wp.pl

23 Department of Population Medicine and Civilization Diseases Prevention, Medical University of Bialystok, 15-269 Bialystok, Poland; fizklin@wp.pl

* Correspondence: grzegorzkrakow1@gmail.com; Tel.: +48-500-099-734

Received: 3 December 2019; Accepted: 3 January 2020; Published: 8 January 2020

\begin{abstract}
Current knowledge of pulmonary arterial hypertension (PAH) epidemiology is based mainly on data from Western populations, and therefore we aimed to characterize a large group of Caucasian PAH adults of Central-Eastern European origin. We analyzed data of incident and prevalent PAH adults enrolled in a prospective national registry involving all Polish PAH centers. The estimated prevalence and annual incidence of PAH were 30.8/mln adults and 5.2/mln adults, respectively and they were the highest in females $\geq 65$ years old. The most frequent type of PAH was idiopathic $(n=444 ; 46 \%)$ followed by PAH associated with congenital heart diseases (CHD-PAH, $n=356 ; 36.7 \%$ ), and PAH associated with connective tissue disease (CTD-PAH, $n=132 ; 13.6 \%$ ). At enrollment, most incident cases $(71.9 \%)$ were at intermediate mortality risk and the prevalent cases had most of their risk factors in the intermediate or high risk range. The use of triple combination therapy was rare $(4.7 \%)$. A high prevalence of $\mathrm{PAH}$ among older population confirms the changing demographics of PAH found in the Western countries. In contrast, we found: a female predominance across all age groups, a high proportion of patients with CHD-PAH as compared to patients with CTD-PAH and a low use of triple combination therapy.
\end{abstract}

Keywords: pulmonary arterial hypertension; registry; epidemiology; prevalence; incidence

\title{
1. Introduction
}

Pulmonary arterial hypertension $(\mathrm{PAH})$ is a rare disease in which progressive narrowing of the pulmonary arterial lumen leads to a rise in pulmonary arterial pressure and pulmonary vascular resistance (PVR) [1]. Currently, most of our knowledge of PAH comes from registries originating in Western populations [2-8]. However, taking a global view of PAH epidemiology shows important geographical differences in the characteristics of PAH patients [9-11].

In Poland, as in other countries of the former Eastern Bloc, the transformation of the political system, started in the early 1990s, opened the health care system to influences from Western medicine. Still, it was not until 2008, that the first PAH targeted therapies were formally reimbursed. Consequently, advanced diagnostics and treatments of PAH were available about two decades later than in the Western countries.

The Data Base of Pulmonary Hypertension in the Polish Population (Baza Nadciśnienia Płucnego; BNP-PL, https://clinicaltrials.gov/ct2/show/NCT03959748) is the first multicenter prospective registry of adult and pediatric PAH and chronic thromboembolic pulmonary hypertension (CTEPH) patients created in any Central-Eastern European country [12].

In the present report, we present the prevalence of PAH in Polish adults and their baseline characteristics including hemodynamics, exercise capacity, comorbidities and disease management. 


\section{Experimental Section}

\subsection{Design of the BNP-PL Registry-PAH Adults Arm}

The design of the BNP-PL registry, enrollment criteria and data collection were recently described in detail [12]. The PAH adult arm of the registry enrolls adults with PAH from all $21 \mathrm{PH}$ reference centers in Poland accredited by the National Health Fund to treat PAH. The protocol of the study was reviewed and accepted by the Bioethical Committee of Physicians and Dentists Chamber in Krakow.

\subsection{Analysis of PAH Patients}

For the purpose of the present study, we analyzed the data of newly and previously diagnosed PAH adult ( $\geq 18$ years old) patients who were under the care of the participating centers between 1 March 2018 and 30 September 2018. The diagnostic algorithm was based on current recommendations [11,13-19]. Newly diagnosed patients were those whose diagnosis was established since 1 March 2018 (termed 'incident cases'). Patients who were diagnosed earlier have been classified as 'prevalent cases'. PAH was defined and classified according to the guidelines of the European Society of Cardiology [15] (ESC; Methods 1 (in Appendix A)). The main goal of our registry is to describe current practice and outcomes in patients with PAH therefore the registry is entirely observational and the protocol of the study does not require any additional patient visits or diagnostic tests, and does not influence the management of patients. We also did not prepare any specific protocol for genetic testing. The diagnosis of IPAH was at the discretion of coinvestigators who managed the enrolled patients in their centers. However, the diagnosis must have fulfilled the criteria recommended by the European Society of Cardiology. This means that patients were diagnosed for PAH when left heart disease, chronic thromboembolic disease, and pulmonary diseases were excluded. IPAH could have been diagnosed only in patients in whom congenital heart defects, connective tissue disease, HIV infection, portal hypertension and possible relation to drug use were excluded. We enrolled in our study reference centers of PAH accredited by the National Health Fund which ensures validity and credibility of the diagnostic algorithms. However, we cannot exclude some variability in the diagnostic approach of different centers which we did not study in detail for the purpose of the present analysis.

As genetic testing is not routinely performed in PAH patients in Poland currently, we cannot make conclusions regarding the prevalence of heritable PAH (HPAH) from our registry. Accordingly, IPAH patients and patients in whom HPAH was diagnosed have been considered as a single group IPAH/HPAH. As PAH treatment can only be reimbursed in accredited centers, we believe that almost all patients diagnosed with PAH have been included in the project.

\subsection{Risk Assessment}

We calculated the initial risk of all incident patients based on the recently proposed grading system of the Swedish PAH Register (SPAHR; Methods 2 (in Appendix A)) [6,20]. The risk of prevalent patients was illustrated by the proportion of patients who achieved a low, intermediate or high risk range for different risk determinants including World Health Organization Functional Class (WHO FC), 6-min walking distance (6 MWD), N-terminal pro-brain natriuretic peptide (NT-proBNP) or BNP, right atrial area (RAA), right atrial pressure (RAP), and cardiac index (CI).

\subsection{Statistical Analysis}

Continuous variables were reported as means (SD). Categorical variables were reported as counts and percentages. Continuous variables were checked for normal distribution with chi-square test. For the comparison of continuous variables between 2 groups, we used the Student's $t$ test and for categorical variables, the $\chi^{2}$ test with Yate's correction as needed. The significance level was set at alpha level of 0.05. Statistical analysis was performed with the use of Dell Inc. (2016), Dell Statistica (data analysis software system), (version 13, Dell, Texas, TX, USA) software.dell.com. 


\section{Results}

\subsection{Study Group}

A total of 1002 adult patients of Caucasian origin with PAH were entered into the electronic data base. The information pertaining to 32 of the patients was identified as being duplicated in the dataset and so these duplicate entries were discarded. Finally, 970 PAH patients met the study entry criteria based on hemodynamic criteria and these patients were enrolled in the present analysis. In a group of $96(9.9 \%)$ incident cases the time from the first symptoms to first medical contact was $9.6 \pm 27.3$ months and from the first symptoms to PAH diagnosis was $12.6 \pm 28.7$ months. In 874 (90.1\%) prevalent patients the time from PAH diagnosis to BNP-PL enrollment was $88.3 \pm 104.9$ months. Women accounted for the majority of the patients $(n=677 ; 69.8 \%)$. The mean age of patients was $46.8 \pm 22.3$ years (females $47.9 \pm 22.1$ vs. males $44.3 \pm 22.7, p=0.005$ ) at diagnosis and $53.8 \pm 17.9$ years (females $55.0 \pm 17.7$ vs. males $50.9 \pm 17.9 ; p<0.0001$ ) at enrollment. A significant number of patients $(n=322 ; 33.2 \%)$ were at least 65 years old. Women accounted for the majority of patients in both the older ( $\geq 65$ years) group $(n=239 ; 74.2 \%)$ and the younger ( $<65$ years) group $(438 ; 67.6 \%)$. Characterization of the study group is presented in Table 1.

Table 1. Patients with Pulmonary Arterial Hypertension in the Data Base of Pulmonary Hypertension in the Polish Population (BNP-PL) Registry.

\begin{tabular}{|c|c|c|c|c|c|c|c|}
\hline & All & I/HPAH & CTD & CHD & Portal & $\begin{array}{l}\text { Drugs/ } \\
\text { Toxins }\end{array}$ & HIV \\
\hline No of patients & 970 & 444 & 132 & 356 & 25 & 7 & 6 \\
\hline Age (years) & $46.8 \pm 22.3$ & $54.6 \pm 18.2$ & $60.4 \pm 13.9$ & $31.5 \pm 21.6$ & $53.7 \pm 21.6$ & $57.1 \pm 14.4$ & $37.7 \pm 5.0$ \\
\hline \multicolumn{8}{|c|}{ Data acquired at diagnosis } \\
\hline \multicolumn{8}{|c|}{ WHO FC, n (\%) } \\
\hline I & $6(0.6)$ & $3(0.8)$ & $1(0.8)$ & $2(0.6)$ & 0 & 0 & 0 \\
\hline II & $159(16.4)$ & $76(17)$ & $17(12.9)$ & $56(15.7)$ & $6(24.0)$ & $2(28.6)$ & $2(33.3)$ \\
\hline III & $699(72.1)$ & $293(66)$ & $96(72.7)$ & $289(81.2)$ & $16(64.0)$ & $2(28.6)$ & $3(50.0)$ \\
\hline IV & $106(10.9)$ & $72(16.2)$ & $18(13.6)$ & $9(2.5)$ & $3(12.0)$ & $3(42.8)$ & $1(16.7)$ \\
\hline Age (years) & $53.8 \pm 17.9$ & $58.7 \pm 16.9$ & $63.8 \pm 13.1$ & $43.8 \pm 16.3$ & $56.4 \pm 14.6$ & $58.2 \pm 12.9$ & $41.1 \pm 5.4$ \\
\hline \multicolumn{8}{|c|}{ Data acquired at enrollment } \\
\hline Female, n (\%) & $677(69.8)$ & $318(71.6)$ & $115(87.1)$ & $223(62.4)$ & $15(60)$ & $3(42.9)$ & $3(50)$ \\
\hline Incident cases, $\mathrm{n}(\%)$ & $96(9.9)$ & $48(10.8)$ & $20(15.1)$ & $19(5.3)$ & $5(20)$ & $1(14.3)$ & $3(50)$ \\
\hline \multicolumn{8}{|c|}{ WHO FC, n (\%) } \\
\hline I & $49(5.1)$ & $28(6.5)$ & $6(1.5)$ & $13(4.8)$ & 0 & $2(28.6)$ & 0 \\
\hline II & $455(46.9)$ & $200(45.3)$ & $52(44.8)$ & $187(49.4)$ & $12(48)$ & $2(28.6)$ & $2(33.3)$ \\
\hline III & $429(43.8)$ & $195(43.4)$ & $64(48.5)$ & $151(41.8)$ & $13(52)$ & $2(28.6)$ & $4(66.7)$ \\
\hline IV & $37(4)$ & $21(3.8)$ & $10(5.2)$ & $5(4)$ & 0 & $1(14.3)$ & 0 \\
\hline $6 \mathrm{MWD}[\mathrm{m}]$ & $375 \pm 142$ & $383 \pm 151$ & $344 \pm 138$ & $375 \pm 132$ & $376 \pm 143$ & $415.2 \pm 74$ & $408 \pm 159$ \\
\hline BMI $\left[\mathrm{kg} / \mathrm{m}^{2}\right]$ & $25.8 . \pm 5.5$ & $27.3 \pm 5.4$ & $25.3 \pm 5.1$ & $23.9 \pm 5.4$ & $26.1 \pm 4.5$ & $26.4 \pm 7.9$ & $22.6 \pm 4.9$ \\
\hline NTproBNP [ng/l] * & $1446 \pm 2733$ & $1480 \pm 2815$ & $1881 \pm 2526$ & $1262 \pm 2566$ & $910 \pm 1923$ & $4328 \pm 6926$ & $2529 \pm 2834$ \\
\hline BNP $[\mathrm{ng} / \mathrm{l}]^{*}$ & $310 \pm 648$ & $382 \pm 761$ & $316 \pm 538$ & $237.8 \pm 558$ & - & - & - \\
\hline mPAP [mmHg] & $50.6 \pm 18.9$ & $45.1 \pm 13.9$ & $38.4 \pm 12.6$ & $63.4 \pm 21.8$ & $45.7 \pm 8.8$ & $41.0 \pm 19.7$ & $46.5 \pm 13.8$ \\
\hline PVR [WU] & $7.8 \pm 4.2$ & $8.1 \pm 4.2$ & $7.0 \pm 4.2$ & $14.9 \pm 9.9$ & $6.8 \pm 2.8$ & $6.7 \pm 5.6$ & $8.8 \pm 5.2$ \\
\hline $\mathrm{CI}\left[1 / \mathrm{min} / \mathrm{m}^{2}\right]$ & $2.7 \pm 0.8$ & $2.7 \pm 1.8$ & $2.7 \pm 0.7$ & $2.5 \pm 1.1$ & $3.2 \pm 1.2$ & $2.8 \pm 1.0$ & $2.7 \pm 0.9$ \\
\hline $\mathrm{RAP}[\mathrm{mmHg}]$ & $6.7 \pm 4.3$ & $6.7 \pm 4.3$ & $6.2 \pm 4.3$ & $7.0 \pm 4.1$ & $7.5 \pm 4.3$ & $8.2 \pm 3.5$ & $7.5 \pm 5.3$ \\
\hline PAWP [mmHg] & $8.9 \pm 3.3$ & $9.4 \pm 3.3$ & $9.3 \pm 3.2$ & $8.2 \pm 3.4$ & $9.3 \pm 3.5$ & $7.0 \pm 2.5$ & $8.2 \pm 3.5$ \\
\hline $\mathrm{RAA}\left[\mathrm{cm}^{2}\right]$ & $23.9 \pm 9.2$ & $24.6 \pm 9.2$ & $23.9 \pm 9.8$ & $22.4 \pm 7.45$ & $22.4 \pm 8.7$ & $23.9 \pm 5.9$ & $21.4 \pm 8.6$ \\
\hline
\end{tabular}

* patients with chronic dialysis were excluded from the assessment of brain natriuretic peptide; in two centres BNP was used instead of NT-proBNP. BMI-body mass index, CI-cardiac index, mPAP-mean pulmonary artery pressure, $6 \mathrm{MWD}$-six min walking distance, NT-proBNP-N-terminal pro-B-type Natriuretic Peptide, PAWP - pulmonary artery wedge pressure, PVR - pulmonary vascular resistance, RAA —right atrial area, RAP right atrial pressure, WHO FC-World Health Organization Functional Class WU-Wood unit.

\subsection{Prevalence, Incidence and Geographic Distribution of PAH}

The mean prevalence of PAH was 30.8 per million adults and the estimated incidence rate was 5.2 per million adults per year. They were the highest in older females (Figure 1). As shown in Figures A1 and A2 (in Appendix B), the geographical distribution of $\mathrm{PAH}$ was heterogeneous, ranging from 14.4 per million to 46.6 per million adults in different regions. 


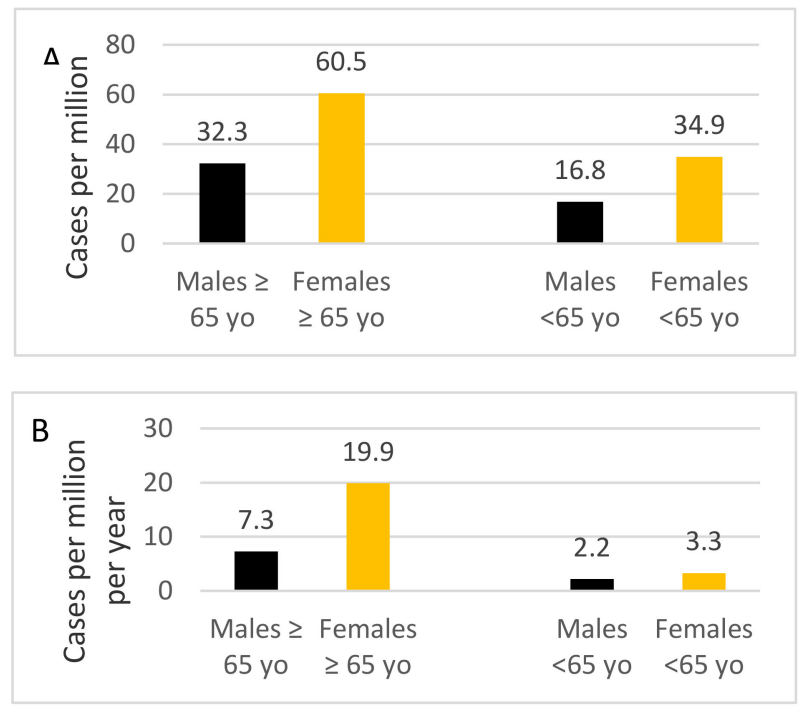

Figure 1. Prevalence (A) and incidence rate (B) of patients with PAH categorized by age and sex.

\subsection{PAH Ssubgroups}

The distribution of PAH subgroups according to the ESC classification at enrollment is shown in Figure 2 and Tables 1 and 2. In the idiopathic/heritable PAH (IPAH/HPAH) group, 75 (16.9\%) patients tested positive for acute vasoreactivity at diagnosis but at enrollment only $39(8.7 \%)$ were still considered vasoreactive. In 13 patients, HPAH was confirmed by genetic testing. Importantly, genetic testing was not routinely performed in Polish PH centers.

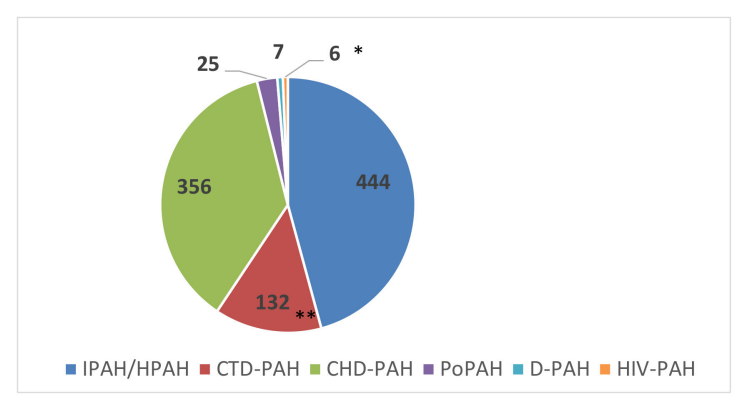

Figure 2. Number of patients with different types of pulmonary arterial hypertension according to clinical classification. In the group of IPAH/HPAH only 12 patients were diagnosed with HPAH based on genetic testing, however PAH patients were not systematically checked for genetic background. CHD-PAH-pulmonary arterial hypertension (PAH) associated with congenital heart disease, CTD-PAH-PAH associated with connective tissue disease, DPAH—drugs and toxin induced PAH, HIV-PAH—PAH associated with HIV infection, HPAH—heritable PAH, IPAH—idiopathic PAH, PoPAH-PAH associated with portal hypertension. * Among patients with CTD-PAH $(n=132)$, the most frequent were diseases of the scleroderma spectrum (SSc-PAH, $n=63$ ) followed by mixed connective tissue disease $(n=22)$, rheumatoid arthritis $(n=15)$, systemic lupus erythematosus $(n=13)$, polimiositis $(n=5)$, and other conditions including overlap syndromes, Sjogren's syndrome, undifferentiated systemic rheumatic disease, and dermatomyositis $(n=14)$. ${ }^{* *}$ In 7 patients, PAH was attributed to the use of drugs and toxins including roxadustat $(n=1)$, dasytinib $(n=3)$, interferon $(n=2)$, and amphetamine $(n=1)$. 
Table 2. The prevalence of different heart defects in four subgroups of patients according to the European Society of Cardiology.

\begin{tabular}{|c|c|c|c|c|}
\hline & $\begin{array}{c}\text { Eisenmenger's } \\
\text { Syndrome } \\
n=265(75 \%)\end{array}$ & $\begin{array}{l}\text { PAH Associated with Prevalent } \\
\text { Systemic-to-Pulmonary Shunts } \\
\qquad n=43(12 \%)\end{array}$ & $\begin{array}{l}\text { PAH after Defect } \\
\text { Correction } \\
n=45(12 \%)\end{array}$ & $\begin{array}{c}\text { PAH with } \\
\text { Small/Coincidental } \\
\text { Defects } \\
n=3(1 \%) \\
\end{array}$ \\
\hline ASD & 39 & 18 & 21 & 1 \\
\hline VSD & 121 & 8 & 8 & 1 \\
\hline AVSD & 42 & 4 & 2 & 0 \\
\hline PDA & 22 & 5 & 4 & 0 \\
\hline Complex defects & 41 & 8 & 10 & 1 \\
\hline
\end{tabular}

\subsection{Demographics and Prognostic Factors}

At diagnosis, most patients $(n=699 ; 72.1 \%)$ were in WHO FC III, while at enrollment in FC II $(n=455 ; 46.9 \%)$. Levels of the main prognostic factors of the study group are shown in Table 1 . In incident cases the baseline risk score was $2.0 \pm 0.4$. Most incident patients were in the intermediate risk $(n=69 ; 71,9 \%)$, followed by $14(14,6 \%)$ in the high and $13(13,5 \%)$ in the low risk. As shown in Table 3 most prevalent patients had their prognostic risk factors of PAH mortality in the range of intermediate or high risk. Most of them were able to achieve normalization of resting CI and RAP but only a quarter of them were able to normalize the RAA.

Table 3. Proportions of Prevalent Patients with Risk Determinants of Pulmonary Arterial Hypertension Mortality in their Low, Intermediate and High Risk Range.

\begin{tabular}{cccc}
\hline Risk Determinants & Low Risk & Intermediate Risk & High Risk \\
\hline WHO FC & $52 \%$ & $44 \%$ & $4 \%$ \\
6 MWD & $41.7 \%$ & $53 \%$ & $5.3 \%$ \\
BNP/NT-proBNP & $40.6 \%$ & $30.8 \%$ & $28.6 \%$ \\
RAA & $25.7 \%$ & $44.8 \%$ & $29.5 \%$ \\
RAP & $65.9 \%$ & $28.7 \%$ & $5.4 \%$ \\
CI & $57.9 \%$ & $22.7 \%$ & $19.4 \%$ \\
\hline
\end{tabular}

The low, intermediate and high risk ranges for the prognostic parameters are as follows: WHO FC I and II, III, IV; 6 MWD >440 m, 165-440 m, <165 m; NT-proBNP <300 ng/L, 300-1400 ng/L, >1400 ng/L; BNP $<50$ ng/150-300 ng/L, $>300 \mathrm{ng} / \mathrm{L} ; \mathrm{RAA}<18 \mathrm{~cm}^{2}, 18-26 \mathrm{~cm}^{2},>26 \mathrm{~cm}^{2} ; \mathrm{RAP}<8 \mathrm{~mm} \mathrm{Hg}, 8-14 \mathrm{~mm} \mathrm{Hg},>14 \mathrm{~mm} \mathrm{Hg} ; \mathrm{CI}>2.5 \mathrm{~kg} / \mathrm{min} / \mathrm{m}^{2}$, $2.0-2.5 \mathrm{~kg} / \mathrm{min} / \mathrm{m}^{2},<2.0 \mathrm{~kg} / \mathrm{min} / \mathrm{m}^{2}$. CI—cardiac index, WHO FC—World Health Organization Functional Class, NT-proBNP-N-terminal pro-B-type Natriuretic Peptide, 6 MWD—six min walking distance, RAA—right atrial area, $\mathrm{RAP}$ - right atrial pressure.

\subsection{Comorbidities and PAH Specific Medications at Enrollment}

The PAH-specific treatments at the time of enrollment among study patients are shown in Table 4. All patients received PAH targeted therapies, apart from 39 patients with reactive IPAH who only received calcium channel blockers for their condition, and 4 patients who did not receive any PAH specific medication (who either did not meet the inclusion criteria for $\mathrm{PAH}$ specific reimbursement or did not agree to the proposed treatment). The numbers of patients treated with monotherapy and combination is shown in Table 4. In Figure A3 (in Appendix B), we show the use of different PAH targeted therapies. In Table 5, we show comorbidities and non-PAH specific treatments identified in PAH patients at enrollment. 
Table 4. PAH-Specific Medications Among Adult PAH Patients in the Data Base of Pulmonary Hypertension in the Polish Population (BNP-PL) Registry at Enrollment.

\begin{tabular}{|c|c|c|c|c|c|c|c|}
\hline All Patients & Whole Sample: & I/HPAH & CTD & CHD & Portal & Drugs/Toxins & HIV \\
\hline Monotherapy $(n, \%)$ & $366(37.7)$ & $123(27.7)$ & $58(43.9)$ & $163(45.8)$ & $15(60)$ & $3(42.9)$ & $4(66.7)$ \\
\hline -Oral $(n, \%)$ & $356(36.7)$ & $117(26.3)$ & $57(43.2)$ & $160(44.9)$ & $15(60)$ & $3(42.9)$ & $4(66.7)$ \\
\hline PDE5-I $(n, \%)$ & 201 & 105 & 22 & 54 & 13 & 3 & 4 \\
\hline $\operatorname{ERA}(n, \%) *$ & 148 & 4 & 141 & 1 & 2 & 0 & 0 \\
\hline -Prostacyclin analogue $(n, \%)$ & $10(1)$ & $6(1.3)$ & $1(0.7)$ & $3(0.8)$ & 0 & 0 & 0 \\
\hline Double comb. therapy $(n, \%)$ & $515(53)$ & $254(57.2)$ & $72(54.5)$ & $173(48.6)$ & $10(40)$ & $4(57.1)$ & $2(33.3)$ \\
\hline -Oral $(n, \%) *$ & $295(30.4)$ & $118(26.6)$ & $33(27.3)$ & $141(39.6)$ & $2(8)$ & 0 & $1(16.7)$ \\
\hline -With prostacyclin analogue $(n, \%)$ & $220(22.7)$ & $136(30.6)$ & $39(29.5)$ & $32(8.9)$ & $8(32)$ & $4(57.1)$ & $1(16.7)$ \\
\hline Triple combination therapy $(n, \%)$ & $46(4.7)$ & $29(6.5)$ & $8(6)$ & $9(2.5)$ & 0 & 0 & 0 \\
\hline \multicolumn{8}{|l|}{ Patients with WHO FC IV: } \\
\hline Monotherapy $(n, \%)$ & 7 (18.9) & $3(14.3)$ & 0 & $4(80)$ & 0 & 0 & 0 \\
\hline -Oral $(n, \%)$ & $7(18.9)$ & $3(14.3)$ & 0 & $4(80)$ & 0 & 0 & 0 \\
\hline -Prostacyclin analogue $(n, \%)$ & 0 & 0 & 0 & 0 & 0 & 0 & 0 \\
\hline Double combination therapy $(n, \%)$ & $21(56.8)$ & $13(61.9)$ & $7(70)$ & 0 & 0 & $1(100)$ & 0 \\
\hline- Oral $(n, \%)$ & $5(13.5)$ & $3(14.3)$ & 2 & 0 & 0 & 0 & 0 \\
\hline -With prostacyclin analogue $(n, \%)$ & $16(43.2)$ & $10(47.6)$ & 5 & 0 & 0 & $1(100)$ & 0 \\
\hline Triple combination therapy $(n, \%)$ & $9(24.3)$ & $5(23.8)$ & $3(30)$ & $1(20)$ & 0 & 0 & 0 \\
\hline
\end{tabular}

* Of 356 patients who used oral monotherapy 349 (98\%) were receiving sildenafil or endothelin receptor antagonist. The other seven patients were receiving riociguat or selexipag which were available only in open label phases of clinical studies and were not formally reimbursed by the National Health Fund. ** Of 295 patients who used oral double combination therapy 292 (99\%) patients used endothelin receptor antagonist and sildenafil, three other patients were using a combination of riociguat and bosentan, or selexipag and sildenafil. ERA-endothelin receptor antagonist, PDE5-I-phosphodiesterase type 5 inhibitor, WHO FC -World Health Organization Functional Class.

Table 5. Concomitant diseases and their treatments.

\begin{tabular}{|c|c|c|c|c|c|c|c|}
\hline & $\begin{array}{c}\text { All } \\
\text { Patients }\end{array}$ & I/HPAH & CTD & CHD & Portal & Drugs/Toxins & HIV \\
\hline Hypertension $(n, \%)$ & $369(38.0)$ & $222(50.0)$ & $71(53.8)$ & $62(17.4)$ & $10(40)$ & $2(28.6)$ & $2(33.3)$ \\
\hline Underweight $(n, \%)$ & $53(5.5)$ & $7(1.6)$ & $9(6.8)$ & $36(10.1)$ & 0 & 0 & $1(16.7)$ \\
\hline Overweight $(n, \%)$ & $300(30.9)$ & $147(33.1)$ & $46(34.8)$ & $94(26.4)$ & $12(0.48)$ & $1(14.2)$ & 0 \\
\hline Obesity $(n, \%)$ & $197(20.3)$ & $130(36.5)$ & $20((15,1)$ & $40(11.2)$ & $4(0.16)$ & $2(28.4)$ & $1(16.7)$ \\
\hline Diabetes mellitus $(n, \%)$ & $154(15.8)$ & $109(24.5)$ & $27(20.5)$ & $13(3.6)$ & $3(12)$ & $1(14.3)$ & $1(16.7)$ \\
\hline \multicolumn{8}{|l|}{ Smoking } \\
\hline -Active $(n, \%)$ & $41(4.2)$ & $23(5.2)$ & $2(1.5)$ & $10(2.8)$ & $3(12)$ & $1(14.3)$ & $2(33.3)$ \\
\hline -Previously $(n, \%)$ & $192(19.8)$ & $116(26.1)$ & $27(20.5)$ & $35(9.8)$ & $8(0.32)$ & $2(28.6)$ & $4(66.6)$ \\
\hline $\operatorname{CAD}(n, \%)$ & $113(11.6)$ & $82(18.5)$ & $17(12.9)$ & $10(2.8)$ & $2(8)$ & $1(14.3)$ & $1(16.7)$ \\
\hline Myocardial infarction $(n, \%)$ & $42(4.3)$ & $28(6.3)$ & $9(6.8)$ & $3(0.8)$ & 0 & $1(14.3)$ & $1(16.7)$ \\
\hline Depression $(n, \%)$ & $55(5.6)$ & $21(4.7)$ & $14(10.6)$ & $7(4.8)$ & $3(12)$ & 0 & 0 \\
\hline $\operatorname{COPD}(n, \%)$ & $73(7.5)$ & $45(10.1)$ & $8(6.1)$ & $20(5.6)$ & 0 & 0 & 0 \\
\hline Asthma $(n, \%)$ & $54(5.6)$ & $27(6)$ & $4(3)$ & $22(6.2)$ & 0 & $1(14.3)$ & 0 \\
\hline Hypothyroidism $(n, \%)$ & $212(21.9)$ & $76(17.1)$ & $31(23.4)$ & $101(28.3)$ & $3(12)$ & $1(14.3)$ & 0 \\
\hline Hyperthyoidism $(n, \%)$ & $26(2.7)$ & $18(4.1)$ & $2(1.5)$ & $6(1.7)$ & 0 & 0 & 0 \\
\hline Liver cirrhosis $(n, \%)$ & $32(3.3)$ & $9(2.0)$ & 0 & $1(0.3)$ & $20(80)$ & 0 & $2(33.3)$ \\
\hline $\operatorname{CKD}(\mathrm{n}, \%)$ & $147(15.2)$ & $82(18.5)$ & $27(20.5)$ & $34(9.6)$ & 0 & $1(14.3)$ & $3(50)$ \\
\hline Dialysis $(n, \%)$ & $5(0.5)$ & $4(0.9)$ & 0 & 0 & 0 & 0 & $1(16.7)$ \\
\hline Endocarditis history $(n, \%)$ & $9(0.9)$ & $2(0.5)$ & $1(0.8)$ & $6(1.7)$ & 0 & 0 & 0 \\
\hline Atrial fibrillation $(n, \%)$ & $166(17.1)$ & $87(19.6)$ & $18(13.6)$ & $56(15.7)$ & $3(12)$ & $2(28.6)$ & 0 \\
\hline Atrial flutter $(n, \%)$ & $52(5.4)$ & $25(5.6)$ & $5(3.8)$ & $22(6.2)$ & 0 & 0 & 0 \\
\hline Down syndrome $(n, \%)$ & $95(9.8)$ & $2(0.5)$ & $1(0.8)$ & $92(25.8)$ & 0 & 0 & 0 \\
\hline Mental retardation $(n, \%)$ & $106(10.9)$ & $5(1.1)$ & $1(0.8)$ & $100(28.1)$ & 0 & 0 & 0 \\
\hline Cancer history $(n, \%)$ & $63(6.5)$ & $39(8.9)$ & $10(7.6)$ & $9(2.5)$ & $3(12)$ & $2(28.6)$ & 0 \\
\hline PE history $(n, \%)$ & $35(3.6)$ & $22(4.9)$ & $5(3.8)$ & $6(1.7)$ & $1(4)$ & 0 & $1(16.7)$ \\
\hline Sleep apnea syndrome $(n, \%)$ & $14(1.4)$ & $11(2.5)$ & $1(0.8)$ & $1(0.3)$ & 0 & $1(14.3)$ & 0 \\
\hline Cardiac pacing $(n, \%)$ & $31(3.2)$ & $13(2.9)$ & $3(2.2)$ & $15(4.2)$ & 0 & 0 & 0 \\
\hline \multicolumn{8}{|l|}{ Therapies $(n, \%)$ : } \\
\hline Home oxygen therapy & $103(10.6)$ & $60(13.5)$ & $26(19.7)$ & $16(4.5)$ & $1(4)$ & 0 & 0 \\
\hline Vitamin $\mathrm{K}$ antagonists & $181(18.7)$ & $98(22.1)$ & $15(11.4)$ & $66(18.5)$ & 0 & $2(28.6)$ & 0 \\
\hline Low-molecular heparin & $27(2.8)$ & $12(2.7)$ & $4(3)$ & $9(2.5)$ & $1(4)$ & 0 & $1(16.7)$ \\
\hline New oral anticoagulants & $86(8.9)$ & $47(10.6)$ & $16(12.1)$ & $22(6.2)$ & $1(4)$ & 0 & 0 \\
\hline Beta blockers * & $396(40.8)$ & $170(38.3)$ & $66(50.0)$ & $137(38.4)$ & $18(72)$ & $2(28.6)$ & $3(50)$ \\
\hline ACEI & $186(19.2)$ & $96(21.6)$ & $34(25.8)$ & $47(13.2)$ & $5(20)$ & $2(28.6)$ & $2(33.3)$ \\
\hline ARB & $67(6.9)$ & $36(8.6)$ & $16(12.1)$ & $15(4.2)$ & 0 & 0 & 0 \\
\hline Ivabradine & $20(2.1)$ & $13(2.9)$ & $2(1.5)$ & $4(1.1)$ & 0 & $1(14.3)$ & 0 \\
\hline Amiodarone & $32(3.3)$ & $20(4.5)$ & $2(1.5)$ & $9(2.5)$ & $1(4)$ & 0 & 0 \\
\hline Other antiarrhythmics & $68(7)$ & $32(7.2)$ & $10(7.6)$ & $26(7.3)$ & 0 & 0 & 0 \\
\hline Loop diuretics & $383(39.5)$ & $130(29.3)$ & $43(35.6)$ & $200(56.2)$ & $6(24)$ & $2(28.6)$ & $2(33.3)$ \\
\hline Thiazide diuretics & $75(7.7)$ & $42(9.5)$ & $13(9.8)$ & $18(5.1)$ & $2(8)$ & 0 & 0 \\
\hline Potassium-sparing diuretics & $368(37.9)$ & $173(38.5)$ & $49(37.1)$ & $124(34.8)$ & $15(60)$ & $4(57.1)$ & $3(50)$ \\
\hline
\end{tabular}


Table 5. Cont.

\begin{tabular}{cccccccc}
\hline & $\begin{array}{c}\text { All } \\
\text { Patients }\end{array}$ & I/HPAH & CTD & CHD & Portal & Drugs/Toxins & HIV \\
& $47(4.8)$ & $19(4.3)$ & $6(4.5)$ & $19(5.3)$ & $2(8)$ & $1(14.3)$ & 0 \\
SSRI & $38(3.9)$ & $20(4.5)$ & $11(8.3)$ & $7(1.9)$ & 0 & 0 & 0 \\
Other antidepressants & $140(14.4)$ & $71(15.9)$ & $25(18.9)$ & $40(11.2)$ & $2(8)$ & $1(14.3)$ & $1(16.7)$ \\
ASA & $15(1.5)$ & $10(2.3)$ & $2(1.5)$ & $2(0.6)$ & 0 & $1(14.3)$ & 0 \\
Clopidogrel & $366(38.9)$ & $190(42.7)$ & $89(67.4)$ & $66(18.5)$ & $15(60)$ & $3(42.9)$ & $3(50)$ \\
Proton pomp inhibitors & $270(27.8)$ & $174(39.1)$ & $39(29.5)$ & $54(15.2)$ & $2(8)$ & $1(14.3)$ & 0 \\
Statins & $87(8.9)$ & $19(4.5)$ & $59(44.7)$ & $4(1.1)$ & $4(16)$ & 0 & $1(16.7)$ \\
Corticosteroids & $68(7.0)$ & $10(2.2)$ & $49(37.1)$ & $2(0.6)$ & $3(12)$ & $2(28.6)$ & $2(33.3)$ \\
\hline Immunosuppressive drugs & &
\end{tabular}

ACEI-angiotensin convertase inhibitors, ARB-angiotensin receptor blockers, ASA-acetylsalicylic acid, CAD—coronary artery disease, CHD—congenital heart disease, CKD—chronic kidney disease, COPD—chronic obstructive pulmonary disease, CTD — connective tissue disease, IPAH—idiopathic pulmonary arterial hypertension, HPAH-hereditary pulmonary arterial hypertension, PE-pulmonary embolism, SSRI-Selective Serotonin Reuptake Inhibitors. * The following beta-blockers were used by PAH patients in the present study: bisoprolol $(n=165,17 \%)$, nebivolol $(n=92 ; 9.5 \%)$, metoprolol $(n=90 ; 9.3 \%)$, carvedilol $(n=30 ; 3.1 \%)$, propranolol $(n=10 ; 1 \%)$, sotalol $(n=5 ; 0.5 \%)$, betaxolol $(n=4 ; 0.4 \%)$.

\subsection{Prevalent and Incident Cases}

The incident as compared to the prevalent cases (Table 6) were older, had more comorbid conditions, and higher proportion of PAH associated with connective tissue disease (CTD-PAH) to $\mathrm{PAH}$ associated with congenital heart disease (CHD-PAH).

Table 6. Comparison of incident and prevalent patients with pulmonary arterial hypertension.

\begin{tabular}{|c|c|c|c|}
\hline & Incident Cases & Prevalent Cases & $p$ \\
\hline Number & 96 & 874 & \\
\hline Age [years] & $62.7 \pm 16.9$ & $52.7 \pm 17.7$ & $<0.0001$ \\
\hline Female sex $(n, \%)$ & $69(71.8)$ & $608(69.6)$ & 0.6 \\
\hline BMI $\left[\mathrm{kg} / \mathrm{m}^{2}\right]$ & $27.4 \pm 5.6$ & $25.7 \pm 5.4$ & 0.0003 \\
\hline \multicolumn{4}{|l|}{ Diagnosis $(n, \%)$ : } \\
\hline IPAH/HPAH & $48(50.0)$ & $396(45.3)$ & 0.03 \\
\hline CTD-APAH & $20(20.8)$ & $112(12.8)$ & 0.03 \\
\hline CHD-APAH & $19(19.8)$ & $337(38.8)$ & 0.0003 \\
\hline \multicolumn{4}{|l|}{ WHO-FC } \\
\hline I & $1(1)$ & $48(5.5)$ & \multirow{4}{*}{$<0.0001$} \\
\hline II & $15(15.6)$ & $440(50.3)$ & \\
\hline III & $63(65.6)$ & $366(42.9)$ & \\
\hline IV & $17(17.7)$ & $20(2.3)$ & \\
\hline $6 \mathrm{MWD}[\mathrm{m}]$ & $289 \pm 136$ & $384 \pm 140$ & $<0.0001$ \\
\hline NTproBNP [ng/L] & $3133.7 \pm 5367.9$ & $1670.1 \pm 7653.8$ & 0.07 \\
\hline $\operatorname{RAA}\left[\mathrm{cm}^{2}\right]$ & $25.3 \pm 8.1$ & $23.8 \pm 9.3$ & 0.16 \\
\hline \multicolumn{4}{|l|}{ Right heart catheterization: } \\
\hline $\mathrm{CI}\left[1 / \mathrm{min} / \mathrm{m}^{2}\right]$ & $2.4 \pm 0.95$ & $2.8 \pm 0.86$ & 0.22 \\
\hline $\mathrm{mPAP}[\mathrm{mmHg}]$ & $45.5 \pm 15.1$ & $51.2 \pm 19.3$ & 0.006 \\
\hline PVR [WU] & $8.9 \pm 4.5$ & $9.7 \pm 7.3$ & 0.35 \\
\hline $\mathrm{RAP}[\mathrm{mmHg}]$ & $7.4 \pm 4.7$ & $6.7 \pm 4.4$ & 0.61 \\
\hline \multicolumn{4}{|l|}{ Concomitant diseases $(\mathrm{n}, \%)$ : } \\
\hline Hypertension & $55(57.3)$ & $314(35.9)$ & $<0.0001$ \\
\hline Diabetes mellitus & $28(29.1)$ & $126(14.4)$ & 0.002 \\
\hline Smoking & $6(6.3)$ & $35(4.0)$ & 0.3 \\
\hline Previous smoking & $33(34)$ & $159(18)$ & 0.0002 \\
\hline Coronary artery disease & $21(21.8)$ & $92(10.5)$ & 0.001 \\
\hline Myocardial infarction & $9(9.4)$ & $33(3.8)$ & 0.01 \\
\hline Chronic kidney disease & 19(19.8) & $128(14.6)$ & 0.18 \\
\hline Atrial fibrillation & $24(25.0)$ & $142(16.2)$ & 0.08 \\
\hline Atrial flutter & $4(4.2)$ & $48(5.5)$ & 0.88 \\
\hline
\end{tabular}

BMI-body mass index, IPAH—idiopathic pulmonary arterial hypertension, CHD—congenital heart disease, $\mathrm{CI}$-cardiac index, $\mathrm{CTD}$ - connective tissue disease, $\mathrm{mPAP}$ - mean pulmonary artery pressure, $6 \mathrm{MWD}$-six min walking distance, NT-proBNP-N-terminal pro-B-type Natriuretic Peptide, PVR-pulmonary vascular resistance, RAA—right atrial area, RAP—right atrial pressure, WHO-FC—World Health Organization Functional Class. 


\section{Discussion}

The present analysis of the BNP-PL registry shows demographics, treatment and the burden of coexisting diseases in a large group of Caucasian adults of Central-Eastern European origin with all types of PAH.

Both, the prevalence and incidence of PAH were the highest among older population which confirms the changing demographics of PAH found previously in the Western countries. In contrast to the Western European and US registries we found a female predominance not only in the younger patients but also in an older population, a high proportion of patients with CHD-PAH as compared to patients with CTD-PAH, and the low use of triple combination therapy.

\subsection{Prevalence of $P A H$}

PAH has been previously shown to be a rare disease with a prevalence ranging from 15 to 52 cases per million population. In the Scottish study [21] based on data from the national reference center responsible for the diagnosis and treatment of all PAH cases in Scotland, PAH was identified in 26 patients per million population. In the French PAH registry [22], based on data from 17 University hospitals, the prevalence of PAH was lower than in the Scottish study and was estimated at 15 cases per million adults. The authors reported this data to be an underestimate since a significant number of patients were known to be treated outside the reference centers which were included in the registry. Additionally, they reported marked differences in regional prevalence of $\mathrm{PAH}$, ranging from five to 25 cases per million population, indicating that many patients were still unidentified or not referred to specialized centers. Our estimations of PAH prevalence are close to 30 patients per million adult population. This number refers to all PAH patients who had been diagnosed with PAH in centers who have a contract with the National Health Fund (NHF) for treatment for PAH. As NHF is the only health payer in Poland, we assume that almost all Polish patients diagnosed with PAH were enrolled in our registry. Nevertheless, we believe that our data still represents a lower estimate for PAH prevalence and that the level of awareness of this disease in some regions is insufficient. We base this assumption on the marked differences in regional prevalence of PAH.

\subsection{Age and Sex Distribution}

The prevalence and incidence rate of PAH in our study were the highest in older females. Of interest was also the finding that the incident patients were about 10 years older than prevalent ones. The rise in the mean age of PAH patients has been previously observed in other studies. In the US National Institutes of Health (NIH) registry conducted in the 1980s [23], the mean age of enrolled patients with primary pulmonary hypertension (currently IPAH) was 36.4 years while in the REVEAL study, recruiting patients 30 years later, the mean age in the IPAH group was 53 years [4,24]. In another study [25] the mean age of systematically observed incident IPAH patients increased from 45 years in 2001-2003 to 52 years in 2007-2009. This demographic shift was also reflected in the European COMPERA registry [26] in which incident PAH patients were in their $60 \mathrm{~s}$ at the time of diagnosis. These changing demographics for PAH patients has usually been accounted for by the aging of the populations of Western countries, and increasing awareness of $\mathrm{PH}$ among physicians and patients.

Our data confirm the predominance of female patients across major types of PAH. We found a female-to-male ratio of 2.3 in the total group of PAH patients and 2.5 in the group of patients with IPAH/HPAH, figures similar to those found in most other PAH registries in the Western Europe. In the French and Swedish registry, this ratio was 1.9 and in the Portuguese registry 2.4 [27]. Interestingly, the female predominance was significantly lower in PAH patients enrolled to the COMPERA study, in which the female-to-male ratio was 1.5 [26]. This proportion was related to the age at PAH diagnosis with the female-to-male ratio of 2.3 in patients aged 18-65 years, and 1.2 among the older patients. Similar results where shown in the Swedish registry, where the female-to-male ratio ranged from 1.9 in patients aged less than 45 years to 0.75 in patients aged at least 75 years [6]. In contrast, our study 
found a female predominance across all age groups. We hypothesize that it resulted from the fact that a significant proportion of PAH males did not achieve an older age due to increased mortality from PAH or other diseases as compared to females. Importantly, Polish males live 7.8 years shorter than Polish females. This difference is much lower in the German and Swedish population in which the life expectancy of males as compared to females is respectively 4.6 years and 3.5 years lower [https://www.who.int/gho/countries/en/]. Moreover, a high prevalence of cardiac and pulmonary diseases in elderly males in Poland may prohibit the proper diagnosis of PAH.

\subsection{Types of $P A H$}

The most frequent type of PAH in the BNP-PL registry was IPAH followed by CHD-PAH and CTD-PAH. The high proportion of CHD-PAH (36.7\%) to CTD-PAH (13.6\%) patients marks out our database as different from those of other Western European (11.3\% vs. $15.3 \%$ in the French) or US registries ( $11.5 \%$ vs. $49.9 \%$ in the US REVEAL) [28,29]. In the Portuguese registry, the proportions of CHD-PAH and CTD-PAH were equal, while a higher ratio of CHD-PAH patients was found in the Chinese registry [30]. In the latter, CHD-PAH patients comprised $43 \%$ of the whole $\mathrm{PAH}$ group, being the most frequent type of PAH. The high prevalence of CHD-PAH in China has been attributed to limited access to corrective cardiac surgery in the past which can also explain our findings. The predominance of CHD-PAH found in prevalent cases is no longer seen among newly diagnosed patients which may result both from decreasing incidence of CHD-PAH and higher survival rates in CHD-PAH as compared to CTD-PAH subjects. In the PAH-CHD group, most patients presented with Eisenmenger's syndrome developed as a complication of ventricular septal defects or complex heart defects. Similar proportions were shown previously by other groups [28].

Still the relatively low prevalence of CTD-PAH is noteworthy. Based on the prevalence of systemic sclerosis (SSc) in Poland (9.4 per 100,000) [31] we estimated the prevalence of PAH at $1.8 \%$ in the SSc group, which is significantly lower than that of other European cohorts. For example, in a large population of SSc patients from France and Italy [32], PAH prevalence was 3.6\%. We consider our data as a signal that CTD-PAH patients are lost, either by never getting a diagnosis or by not reaching the designated PAH centre.

\subsection{Therapy, Comorbid Conditions and Risk}

According to the current recommendations most PAH patients should receive a combination of PAH specific therapies. However, given the high costs of specific PAH treatment, the use of particular types of therapy may be a direct effect of the reimbursement policy and healthcare organization.

In the BNP-PL registry, more than a half of patients were treated with a combination therapy. This data parallels a recent analysis of other European registries. In COMPERA, combination therapy was used in $40.3 \%, 49.6 \%$ and $57.5 \%$ of patients in 1-, 2-, and 3-year follow-ups respectively while in the French registry dual or triple combination therapy was initiated in $43 \%$ of patients within three months after PAH diagnosis. The low use of triple combination in our study may be as a result of the fact that it was not reimbursed in Poland until November 2018.

Prostacyclin analogs (treprostinil, epoprostenol, or inhaled iloprost) were used by $28.4 \%$ of the total group and by $38.5 \%$ of IPAH patients. Of note is the relatively high use of prostacyclin in patients who were in WHO FC IV in our study (65.8\%) when compared to the REVEAL registry (47.6\%) [33].

We found that the proportion of PAH patients who were using home oxygen therapy in our study was $10.6 \%$ which is low when compared to data from other registries including the US REVAL registry $(40.3 \%)$ [4], the SPAHR registry (33\%) [34] and the Spanish registry of patients treated with inhaled iloprost (38\%) [35]. This may result from several factors including the lack of data from randomized trials to support oxygen supplementation in PAH subjects, quite liberal recommendations of the ESC for oxygen use in PAH (use only in patients with blood $\mathrm{O}_{2}$ pressure consistently $>60 \mathrm{mmHg}$ ), and a high proportion of patients with CHD-PAH in our study. According to the ESC guidelines in the latter subpopulation of $\mathrm{PAH}$ patients the use of supplemental $\mathrm{O}_{2}$ therapy should be considered only in cases 
in which it produces a consistent increase in arterial $\mathrm{O}_{2}$ saturation and reduces symptoms. We can not also exclude the role of some difficulties with access to oxygen generators.

The baseline risk of our incident PAH patients calculated based on the ESC risk predictors was similar to other major PAH registries. It is however important to note that other factors not included in our analysis may also impact individual patient's risk [36].

The prevalence of coronary artery disease and its classic risk factors, such as hypertension and diabetes was relatively high in patients with IPAH and CTD-PAH, which would suggest that left ventricular dysfunction contributes to the development of pulmonary hypertension in some patients [37]. However, we enrolled into our study only patients with PAWP $\leq 15 \mathrm{mmHg}$ which establishes the diagnosis of precapillary pulmonary hypertension. Additionally, our data is in line with previous studies [25] which show the changing demographics of PAH. It is interesting to note the high usage of therapies generally not advised in PAH such as anticoagulants, beta blockers, and angiotensin enzyme inhibitors. This, however, seems to be due to comorbid conditions such as atrial fibrillation or flutter, ischemic heart disease, and myocardial infarction in the patients' history.

Recently, targeting the negative consequences of chronic sympathetic nerve activation with use of beta-blockers, and renal or pulmonary artery denervation has attracted interest. Till now, however, no clear demonstration of a favorable benefit-to-risk ratio of these therapies in PAH patients has been provided and multicenter randomized trials are needed to adapt their use in clinical practice [38].

In our registry we found that a significant number of patients $(n=127,13 \%)$ had a diagnosis of COPD or asthma. Similar proportions $(21.9 \%)$ were shown in the largest PAH registry conducted in the United States (REVEAL registry) [4]. This means that despite suffering from obstructive lung diseases some patients had been diagnosed with group 1 pulmonary hypertension (PAH). In that way COPD or asthma in a mild form were considered as a comorbid condition in a PAH patient rather than as an etiology of pulmonary hypertension. This approach has been recently supported by the experts of the 6th World Symposium on Pulmonary Hypertension [39], who suggest that in patients who have pulmonary hypertension and obstructive lung disease with FEV1 $>60 \%$ and minimal parenchymal changes, the primary diagnosis should be PAH rather than group 3 pulmonary hypertension.

\subsection{Incident and Prevalent Patients}

Most patients in the BNP-PL registry are prevalent cases which is due to the design of our study. As shown in Table 6, incident patients were older and suffered from more comorbid conditions as compared to prevalent ones. Additionally, CTD-PAH was more commonly diagnosed than CHD-PAH. These changes reflect the changing demographics of the $\mathrm{PAH}$ population observed in the Western populations.

\subsection{Strengths and Limitations}

Our study has several strengths. First of all, our study has enrolled a large group of patients in the era of modern PAH therapies over 10 years after major Europe and US based registries were started. Secondly, due to a specific reimbursement system, we present data for the whole population diagnosed and treated in Poland. Thirdly, we are the first to show the multicenter, prospectively collected data on PAH epidemiology in a Central-Eastern European country with a significantly different political and economic background than Western World countries. Previous reports from this geographical region presented retrospectively collected [40] or single center data [41].

Our study also has several limitations. The first is the small number of newly diagnosed as compared to previously diagnosed patients. Still, this proportion will change significantly as only incident cases will be enrolled in the follow-up part of our study. Secondly, as genetic testing has not been routinely performed in Polish patients, we have identified very few subjects with the BMPR2 gene mutation, which probably does not reflect the true prevalence of HPAH. Thirdly, the group of CTD-PAH patients seems to be underrepresented in our registry which probably results from the lack of national screening programmes in CTD population. Lastly, we merely collect data on the baseline characteristics of our patients rather than any analysis of their prognosis. This, however, will be 
available in the future follow-up analysis. The methodological limitations inherent to registry-based studies have been recently acknowledged [42].

\section{Conclusions}

Our study shows the epidemiology of PAH in a Central-Eastern post-communist European country with a relatively short history of availability of PAH therapies [32]. It estimates the prevalence of adult PAH at a similar level to that observed in the Western countries but highlights heterogeneity in the geographic distribution of $\mathrm{PAH}$, which suggests that an important proportion of patients may still have not been diagnosed. Important differences between prevalent and incident cases show similar demographic trends as in the Western Europe registries. However, it is worth noting the high proportion of patients with CHD-PAH and the relatively low proportion of those with CTD-PAH. Double combination therapy is shown to be used as frequently as in registries from the Western European countries; nonetheless, the use of triple combination therapy even in high risk patients is relatively low. This may be more a reflection of the strict reimbursement conditions rather than any medical neglect, and therefore could be an issue for improvement within the reimbursement policy. This is counterbalanced by a relatively high frequency of parenteral prostanoid therapy in the most severe patients, higher than in previously published registries.

Author Contributions: Data curation, Formal analysis, Methodology, Project administration, G.K.; Investigation, writing-original draft, G.K., M.K., E.M., Ł.C., T.M.-K., I.S., B.K., P.P. (Piotr Podolec), P.B., E.L., D.K., K.M.-S., M.T., W.J., K.P.-K., M.P.-P., A.D., A.P., Z.G., W.Z., R.R., K.W.-P., M.W., S.D., M.F., M.C., J.D.K., M.G., K.K., P.H., P.P. (Piotr Pruszczyk) and A.T. All authors have read and agreed to the published version of the manuscript.

Funding: This research was funded by Polish Cardiac Society.

Conflicts of Interest: Kopec reports grants and personal fees from Actelion Pharma, personal fees from Janssen-Cilag Polska, personal fees from AOP Orphan, personal fees from Polska, outside the submitted work; Kurzyna reports grants and personal fees from Actelion Pharma, Janssen-Cilag, AOP Orphan, and Bayer outside the submitted work; Mroczek reports personal fees from AOP ORPHAN, personal fees from ACTELION, personal fees from BAYER, personal fees from, outside the submitted work; Chrzanowski reports personal fees from Actelion Pharma, personal fees from Janssen-Cilag, personal fees from AOP Orphan, personal fees from, personal fees from Bayer, outside the submitted work; Mularek-Kubzdela reports grants and personal fees from Actelion Pharma, personal fees from Janssen-Cilag Polska, personal fees from AOP Orphan, personal fees from Polska, outside the submitted work; Skoczylas reports personal fees from AOP ORPHAN, personal fees from Actelion, personal fees from, outside the submitted work; Kuśmierczyk-Droszcz reports personal fees from Actelion Pharma, from Janssen-Cilag Polska, from AOP Orphan, from Polska, outside the submitted work; Pruszczyk reports personal fees from Bayer, outside the submitted work; Błaszczak has nothing to disclose Lewicka reports personal fees from Actelion Pharma, personal fees from Polska, personal fees from AOP Orphan, personal fees from Bayer Polska, outside the submitted work; Karasek reports personal fees from Actelion Pharma, personal fees from AOP Orphan, outside the submitted work; Mizia-Stec reports personal fees from Actelion Pharma, personal fees from Janssen-Cilag Polska, personal fees from AOP Orphan, personal fees from Polska, personal fees from Bayer, outside the submitted work; Tomaszewski reports personal fees from Actelion Pharma, personal fees from Janssen-Cilag Polska, personal fees from AOP Orphan, personal fees from Polska, outside the submitted work. Jacheć has nothing to disclose. Ptaszynska-Kopczynska reports personal fees from Actelion Pharma and Janssen-Cilag Polska, outside the submitted work. Małgorzata Peregud-Pogorzelska reports personal fees from Actelion Pharma, personal fees from AOP Orphan, personal fees from Polska, outside the submitted work; Doboszyńska reports personal fees not conected with the article from Boehringer Ingelheim, personal fees from Astra Zeneca Polska, personal fees from Chiesi, personal fees from Actelion, personal fee from LekAm. Pawlak reports personal fees from BAYER, personal fees from AOP ORPHAN, outside the submitted work; Gasior reports personal fees from Actelion Pharma, personal fees from Polska, personal fees from AOP Orphan, personal fees from Bayer Polska, personal fees from Servier Polska, outside the submitted work; Zabłocka has nothing to disclose. Ryczek has nothing to disclose. Widejko-Pietkiewicz has nothing to disclose. Waligóra reports personal fees from Actelion, outside the submitted work; Darocha reports personal fees from Bayer, personal fees from Actelion, personal fees from AOP ORPHAN, personal fees from, outside the submitted work; Furdal reports fees for lectures from Actelion Pharma and AOP Orphan outside the submitted work. Ciurzyński has nothing to disclose. Kasprzak reports personal fees from Actelion Pharma, personal fees from Janssen-Cilag Polska, personal fees from AOP Orphan, personal fees from Bayer Polska, outside the submitted work; Grabka reports personal fees from Actelion Pharma, personal fees from Janssen-Cilag Polska, personal fees from AOP Orphan, personal fees from Bayer Polska, outside the submitted work; Kaminski reports personal fees from Actelion Pharma, personal fees from Janssen-Cilag Polska, personal fees from AOP Orphan, personal fees from Polska, outside the submitted work; Hoffman reports personal fees from Actelion Pharma, outside the submitted work; Podolec reports personal fees from Actelion, personal fees from Jansen, personal fees from AOP ORPHAN, 
personal fees from Bayer, outside the submitted work; Torbicki reports grants and personal fees from Actelion Pharma, personal fees from Janssen-Cilag Polska, personal fees from AOP Orphan, personal fees from Polska, grants and personal fees from Bayer Healthcare, non-financial support from null, outside the submitted work; and Chairperson of the Foundation on Pulmonary Hypertension. Foundation receive donations including those from industry, Chairmanship is a honorary function and is not related with financial or other benefits. The funders had no role in the design of the study; in the collection, analyses, or interpretation of data; in the writing of the manuscript, or in the decision to publish the results.

\section{Appendix A}

Methods S1. The inclusion criteria included the following hemodynamic parameters obtained at right heart catheterization (RHC) at rest: mean pulmonary arterial pressure (mPAP) of $25 \mathrm{~mm} \mathrm{Hg}$ or more, mean pulmonary arterial wedge pressure (PAWP) or left ventricular end-diastolic pressure (PVEDP) of $15 \mathrm{~mm} \mathrm{Hg}$ or less, pulmonary vascular resistance (PVR) of $>3$ Woods Units (WU), and a clinical diagnosis of PAH according to the clinical investigators' judgments, guided by generally accepted definitions. Based on the clinical classification of PAH, the enrolled patients were classified by the investigators as idiopathic (IPAH), heritable (HPAH) or associated with connective tissue disease (CTD-PAH), congenital heart disease (CHD-PAH), portal hypertension (Po-PAH), drugs or toxins (DPAH), HIV infection (HIV-PAH), or schistosomiasis. Patients with (CHD-PAH) were further sub-classified as Eisenmenger's syndrome, PAH associated with prevalent systemic-to-pulmonary shunts, PAH with small/coincidental defects, and PAH after defect correction as previously defined. Patients participating in clinical trials were eligible for enrollment and any information about the phases of the clinical trial and its design (double blinded/open label) was recorded in the data base. Acute pulmonary vasoreactivity for patients with idiopathic, hereditable or drug-induced PAH was defined as a reduction of $\mathrm{mPAP} \geq 10 \mathrm{mmHg}$ to reach an absolute value of $\mathrm{mPAP} \leq 40 \mathrm{mmHg}$ and increased or unchanged cardiac output after vasodilator inhalation. Long-term response to calcium channel blockers was defined as WHO Functional Class I/II with sustained haemodynamic improvement (same or better than achieved in the acute test) after at least 1 year on calcium channel blockers only. Methods S2. As proposed by its authors the following variables were assigned 1, 2 or 3 points according to the cut-off values for low, intermediate and high risk available in the risk assessment table of the ESC guidelines: WHO-FC, 6-min walk distance (6 MWD), N-Terminal pro-brain natriuretic peptide (NT-proBNP) or BNP (depending on availability), area of the right atrium (RAA), right atrial pressure (RAP) and cardiac index (CI). The risk for every incident patient was calculated by dividing the sum of all grades by the number of assessed variables and then was rounded off to the nearest integer to assign patients to specific risk groups. 


\section{Appendix B}

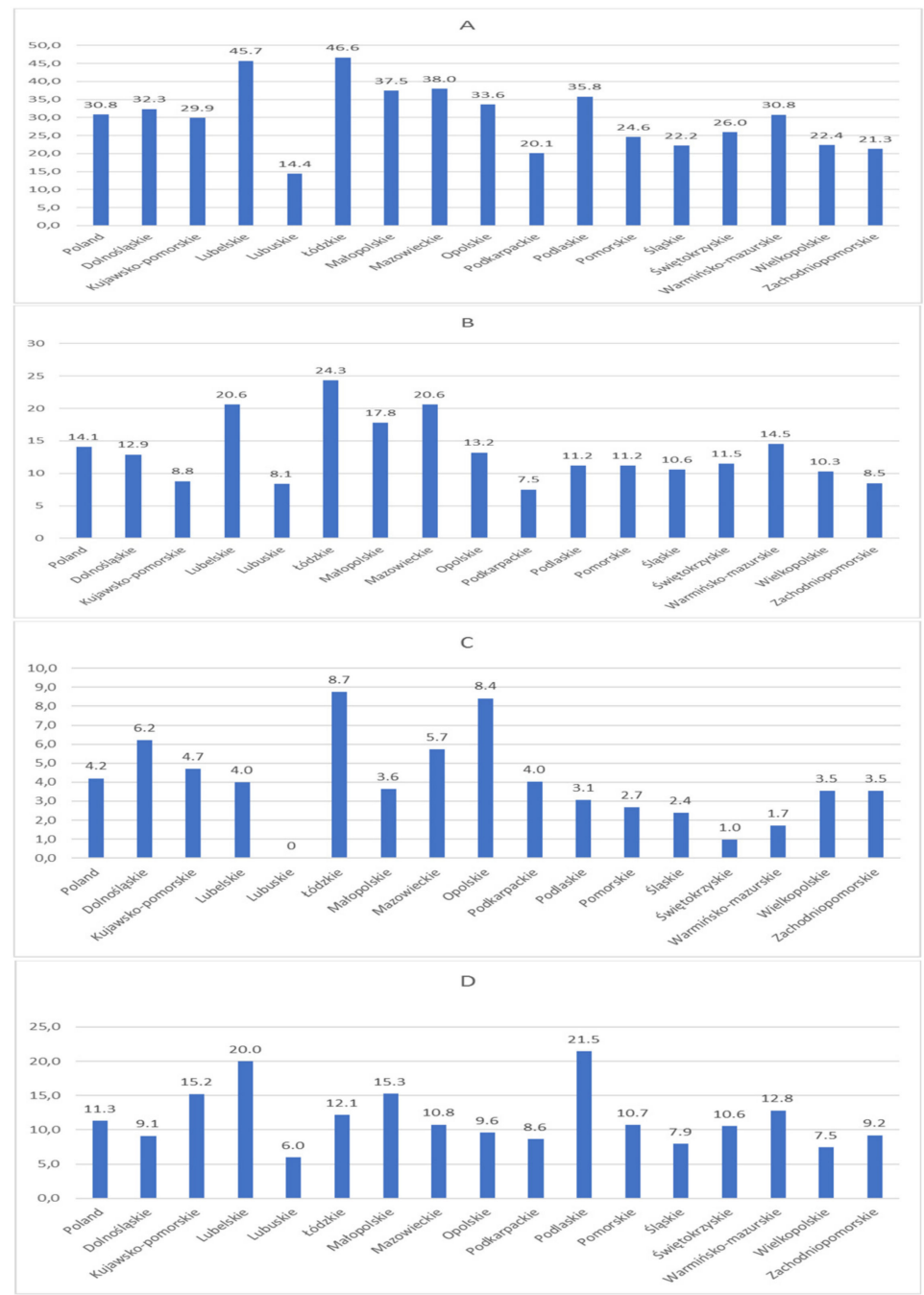

Figure A1. Geographical distribution of patients with pulmonary arterial hypertension (A) and its most frequent subgroups including idiopathic pulmonary arterial hypertension (B), pulmonary arterial hypertension associated with connective tissue disease $(\mathbf{C})$ and pulmonary arterial hypertension associated with congenital heart disease (D).

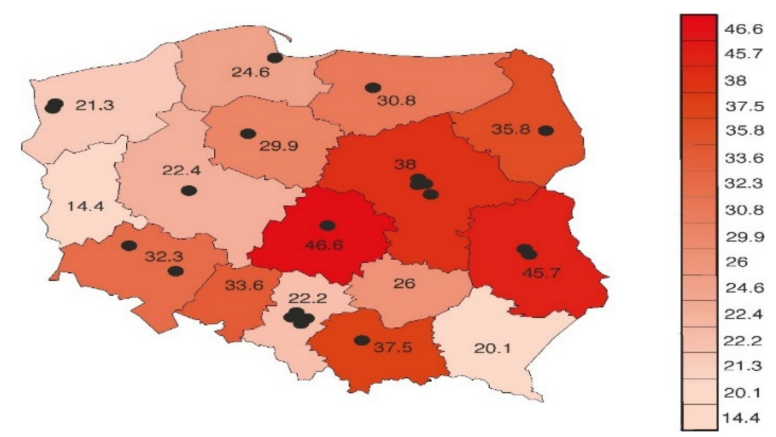

Figure A2. Prevalence of pulmonary arterial hypertension and the numbers of reference pulmonary hypertension centres in different parts of Poland. The number of black dots corresponds with the number of pulmonary hypertension reference centres in each region of Poland. We did not find any significant correlation between the prevalence of pulmonary arterial hypertension and the number of pulmonary hypertension centers per region $(r=0.28, p=0.29)$. 


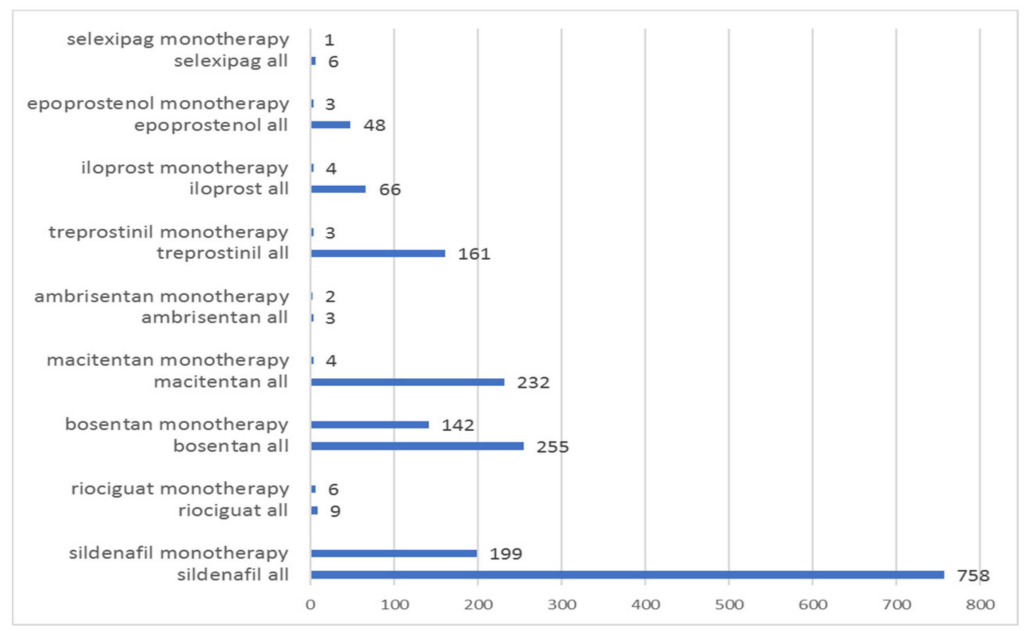

Figure A3. The use of pulmonary hypertension targeted therapies in registry patients. A total of 26 patients were participants in clinical trials at the time of enrollment, including 4 in randomized double-blind placebo-controlled trials and 23 in open-label extension studies.

\section{References}

1. Humbert, M.; Guignabert, C.; Bonnet, S.; Dorfmüller, P.; Klinger, J.R.; Nicolls, M.R.; Olschewski, A.J.; Pullamsetti, S.S.; Schermuly, R.T.; Stenmark, K.R.; et al. Pathology and pathobiology of pulmonary hypertension: State of the art and research perspectives. Eur. Respir. J. 2019, 53, 1801887. [CrossRef] [PubMed]

2. Galiè, N.; Channick, R.N.; Frantz, R.P.; Grünig, E.; Jing, Z.C.; Moiseeva, O.; Preston, I.R.; Pulido, T.; Safdar, Z.; Tamura, Y.; et al. Risk stratification and medical therapy of pulmonary arterial hypertension. Eur. Respir. J. 2019, 53, 1801889. [CrossRef] [PubMed]

3. McGoon, M.D.; Benza, R.L.; Escribano-Subias, P.; Jiang, X.; Miller, D.P.; Peacock, A.J.; Pepke-Zaba, J.; Pulido, T.; Rich, S.; Rosenkranz, S.; et al. Pulmonary arterial hypertension: Epidemiology and registries. J. Am. Coll. Cardiol. 2013, 62, D51-D59. [CrossRef] [PubMed]

4. Badesch, D.B.; Raskob, G.E.; Elliott, C.G.; Krichman, A.M.; Farber, H.W.; Frost, A.E.; Barst, R.J.; Benza, R.L.; Liou, T.G.; Turner, M.; et al. Pulmonary Arterial Hypertension. Chest 2010, 137, 376-387. [CrossRef] [PubMed]

5. Boucly, A.; Weatherald, J.; Savale, L.; Jaïs, X.; Cottin, V.; Prevot, G.; Picard, F.; de Groote, P.; Jevnikar, M.; Bergot, E.; et al. Risk assessment, prognosis and guideline implementation in pulmonary arterial hypertension. Eur. Respir. J. 2017, 50, 1700889. [CrossRef] [PubMed]

6. Kylhammar, D.; Kjellström, B.; Hjalmarsson, C.; Jansson, K.; Nisell, M.; Söderberg, S.; Wikström, G.; Rådegran, G. A comprehensive risk stratification at early follow-up determines prognosis in pulmonary arterial hypertension. Eur. Heart J. 2018, 39, 4175-4181. [CrossRef]

7. Hoeper, M.M.; Kramer, T.; Pan, Z.; Eichstaedt, C.A.; Spiesshoefer, J.; Benjamin, N.; Olsson, K.M.; Meyer, K.; Vizza, C.D.; Vonk-Noordegraaf, A.; et al. Mortality in pulmonary arterial hypertension: Prediction by the 2015 European pulmonary hypertension guidelines risk stratification model. Eur. Respir. J. 2017, 50, 1700740. [CrossRef]

8. Quezada Loaiza, C.A.; Velázquez Martín, M.T.; Jiménez López-Guarch, C.; Ruiz Cano, M.J.; Navas Tejedor, P.; Carreira, P.E.; Flox Camacho, Á.; de Pablo Gafas, A.; Delgado Jiménez, J.F.; Gómez Sánchez, M.Á.; et al. Trends in Pulmonary Hypertension Over a Period of 30 Years: Experience from a Single Referral Centre. Rev. Española Cardiol. 2017, 70, 915-923. [CrossRef]

9. Alves, J.L.; Gavilanes, F.; Jardim, C.; Fernandes, C.J.C. dos S.; Morinaga, L.T.K.; Dias, B.; Hoette, S.; Humbert, M.; Souza, R. Pulmonary Arterial Hypertension in the Southern Hemisphere. Chest 2015, 147, 495-501. [CrossRef]

10. Tamura, Y.; Kumamaru, H.; Satoh, T.; Miyata, H.; Ogawa, A.; Tanabe, N.; Hatano, M.; Yao, A.; Abe, K.; Tsujino, I.; et al. Effectiveness and Outcome of Pulmonary Arterial Hypertension-Specific Therapy in Japanese Patients with Pulmonary Arterial Hypertension. Circ. J. 2017, 82, 275-282. [CrossRef] 
11. Kopeć, G.; Waligóra, M.; Jonas, K.; Stẹpniewski, J.; Magoń, W.; Podolec, P. Epoprostenol therapy for pulmonary arterial hypertension: The first Polish experience. Pol. Arch. Intern. Med. 2019, 129, 65-68. [CrossRef] [PubMed]

12. Kopeć, G.; Kurzyna, M.; Mroczek, E.; Chrzanowski, Ł.; Mularek-Kubzdela, T.; Skoczylas, I.; Kuśmierczyk, B.; Pruszczyk, P.; Błaszczak, P.; Lewicka, E.; et al. Data Base of pulmoNary hyPertension in the PoLish population (BNP-PL)-Design of the registry. Kardiol. Pol. 2019, 77, 972. [CrossRef]

13. Kurzyna, M.; Araszkiewicz, A.; Błaszczak, P.; Grabka, M.; Hawranek, M.; Kopeć, G.; Mroczek, E.; Zembala, M.; Torbicki, A.; Ochała, A. Summary of recommendations for the haemodynamic and angiographic assessment of the pulmonary circulation. Joint statement of the Polish Cardiac Society's Working Group on Pulmonary Circulation and Association of Cardiovascular Interventions. Kardiol. Pol. 2015, 73, 63-68. [CrossRef] [PubMed]

14. Kubiak, G.M.; Ciarka, A.; Biniecka, M.; Ceranowicz, P. Right Heart Catheterization-Background, Physiological Basics, and Clinical Implications. J. Clin. Med. 2019, 8, 1331. [CrossRef] [PubMed]

15. Galiè, N.; Humbert, M.; Vachiery, J.-L.; Gibbs, S.; Lang, I.; Torbicki, A.; Simonneau, G.; Peacock, A.; Vonk Noordegraaf, A.; Beghetti, M.; et al. 2015 ESC/ERS Guidelines for the diagnosis and treatment of pulmonary hypertension: The Joint Task Force for the Diagnosis and Treatment of Pulmonary Hypertension of the European Society of Cardiology (ESC) and the European Respiratory Society (ERS): Endorsed by: Association for European Paediatric and Congenital Cardiology (AEPC), International Society for Heart and Lung Transplantation (ISHLT). Eur. Heart J. 2016, 37, 67-119. [PubMed]

16. Jonas, K.; Kopeć, G. HDL Cholesterol as a Marker of Disease Severity and Prognosis in Patients with Pulmonary Arterial Hypertension. Int. J. Mol. Sci. 2019, 20, 3514. [CrossRef]

17. Jonas, K.; Waligóra, M.; Magoń, W.; Zdrojewski, T.; Stokwiszewski, J.; Płazak, W.; Podolec, P.; Kopeć, G. Prognostic role of traditional cardiovascular risk factors in patients with idiopathic pulmonary arterial hypertension. Arch. Med. Sci. 2019, 15, 1397-1406. [CrossRef]

18. Kopec, G.; Waligóra, M.; Tyrka, A.; Komar, M.; Herman, N.; Podolec, P. Clinical response to calcium channel blockers in a hemodynamically unstable patient with reactive idiopathic pulmonary arterial hypertension. Arch. Med. Sci. 2017, 13, 504. [CrossRef]

19. Picken, C.; Fragkos, K.C.; Eddama, M.; Coghlan, G.; Clapp, L.H. Adverse Events of Prostacyclin Mimetics in Pulmonary Arterial Hypertension: A Systematic Review and Meta-Analysis. J. Clin. Med. 2019, 8, 481. [CrossRef]

20. Rådegran, G.; Kjellström, B.; Ekmehag, B.; Larsen, F.; Rundqvist, B.; Blomquist, S.B.; Gustafsson, C.; Hesselstrand, R.; Karlsson, M.; Kornhall, B.; et al. Characteristics and survival of adult Swedish PAH and CTEPH patients 2000-2014. Scand. Cardiovasc. J. 2016, 50, 243-250. [CrossRef]

21. Peacock, A.J.; Murphy, N.F.; McMurray, J.J.; Caballero, L.; Stewart, S. An epidemiological study of pulmonary arterial hypertension. Eur. Respir. J. 2007, 30, 104-109. [CrossRef] [PubMed]

22. Humbert, M.; Sitbon, O.; Chaouat, A.; Bertocchi, M.; Habib, G.; Gressin, V.; Yaici, A.; Weitzenblum, E.; Cordier, J.-F.; Chabot, F.; et al. Pulmonary arterial hypertension in France: Results from a national registry. Am. J. Respir. Crit. Care Med. 2006, 173, 1023-1030. [CrossRef] [PubMed]

23. D'Alonzo, G.E.; Barst, R.J.; Ayres, S.M.; Bergofsky, E.H.; Brundage, B.H.; Detre, K.M.; Fishman, A.P.; Goldring, R.M.; Groves, B.M.; Kernis, J.T. Survival in Patients with Primary Pulmonary Hypertension. Ann. Intern. Med. 1991, 115, 343. [CrossRef] [PubMed]

24. McGoon, M.D.; Krichman, A.; Farber, H.W.; Barst, R.J.; Raskob, G.E.; Liou, T.G.; Miller, D.P.; Feldkircher, K.; Giles, S. Design of the REVEAL registry for US patients with pulmonary arterial hypertension. Mayo Clin. Proc. 2008, 83, 923-931. [CrossRef]

25. Ling, Y.; Johnson, M.K.; Kiely, D.G.; Condliffe, R.; Elliot, C.A.; Gibbs, J.S.R.; Howard, L.S.; Pepke-Zaba, J.; Sheares, K.K.K.; Corris, P.A.; et al. Changing demographics, epidemiology, and survival of incident pulmonary arterial hypertension: Results from the pulmonary hypertension registry of the United Kingdom and Ireland. Am. J. Respir. Crit. Care Med. 2012, 186, 790-796. [CrossRef]

26. Hoeper, M.M.; Huscher, D.; Ghofrani, H.A.; Delcroix, M.; Distler, O.; Schweiger, C.; Grunig, E.; Staehler, G.; Rosenkranz, S.; Halank, M.; et al. Elderly patients diagnosed with idiopathic pulmonary arterial hypertension: Results from the COMPERA registry. Int. J. Cardiol. 2013, 168, 871-880. [CrossRef]

27. Santos, M.; Gomes, A.; Cruz, C.; Rocha, J.; Ricardo, M.; Gonçalves, F.; Carvalho, L.; Vicente, M.; Melo, A.; Reis, A. Long-term survival in pulmonary arterial hypertension and chronic thromboembolic pulmonary hypertension: Insights from a referral center in Portugal. Rev. Port. Cardiol. 2018, 37, 749-757. [CrossRef] 
28. Brida, M.; Gatzoulis, M.A. Pulmonary arterial hypertension in adult congenital heart disease. Heart 2018, 104, 1568-1574. [CrossRef]

29. Van der Feen, D.E.; Bartelds, B.; de Boer, R.A.; Berger, R.M.F. Assessment of reversibility in pulmonary arterial hypertension and congenital heart disease. Heart 2019, 105, 276-282. [CrossRef]

30. Awdish, R.; Cajigas, H. Definition, epidemiology and registries of pulmonary hypertension. Heart Fail. Rev. 2016, 21, 223-228. [CrossRef]

31. Kanecki, K.; Goryński, P.; Tarka, P.; Wierzba, W.; Tyszko, P. Incidence and prevalence of Systemic Sclerosis (SSc) in Poland-Differences between rural and urban regions. Ann. Agric. Environ. Med. 2017, 24, 240-244. [CrossRef] [PubMed]

32. Avouac, J.; Airò, P.; Meune, C.; Beretta, L.; Dieude, P.; Caramaschi, P.; Tiev, K.; Cappelli, S.; Diot, E.; Vacca, A.; et al. Prevalence of pulmonary hypertension in systemic sclerosis in European Caucasians and metaanalysis of 5 studies. J. Rheumatol. 2010, 37, 2290-2298. [CrossRef] [PubMed]

33. Farber, H.W.; Miller, D.P.; Meltzer, L.A.; McGoon, M.D. Treatment of patients with pulmonary arterial hypertension at the time of death or deterioration to functional class IV: Insights from the REVEAL Registry. J. Heart Lung Transplant. 2013, 32, 1114-1122. [CrossRef] [PubMed]

34. Hjalmarsson, C.; Rådegran, G.; Kylhammar, D.; Rundqvist, B.; Multing, J.; Nisell, M.D.; Kjellström, B. Impact of age and comorbidity on risk stratification in idiopathic pulmonary arterial hypertension. Eur Respir. J. 2018, 51, 1702310. [CrossRef]

35. Del Pozo, R.; Blanco, I.; Hernández-González, I.; López-Meseguer, M.; López-Reyes, R.; Lázaro-Salvador, M.; Elías-Hernández, T.; Álvarez-Vega, P.; Pérez-Peñate, G.M.; Martínez-Meñaca, A.; et al. Real-life experience of inhaled iloprost for patients with pulmonary arterial hypertension: Insights from the Spanish REHAP registry. Int J Cardiol. 2019, 275, 158-164. [CrossRef] [PubMed]

36. Drakopoulou, M.; Nashat, H.; Kempny, A.; Alonso-Gonzalez, R.; Swan, L.; Wort, S.J.; Price, L.C.; McCabe, C.; Wong, T.; Gatzoulis, M.A.; et al. Arrhythmias in adult patients with congenital heart disease and pulmonary arterial hypertension. Heart 2018, 104, 1963-1969. [CrossRef]

37. Mehra, P.; Mehta, V.; Sukhija, R.; Sinha, A.K.; Gupta, M.; Girish, M.P.; Aronow, W.S. Pulmonary hypertension in left heart disease. Arch. Med. Sci. 2019, 15, 262-273. [CrossRef]

38. Perros, F.; De Man, F.S.; Bogaard, H.J.; Antigny, F.; Simonneau, G.; Bonnet, S.; Provencher, S.; Galiè, N.; Humbert, M. Use of $\beta$-Blockers in Pulmonary Hypertension. Circ. Heart Fail. 2017, 10, e003703. [CrossRef]

39. Nathan, S.D.; Barbera, J.A.; Gaine, S.P.; Harari, S.; Martinez, F.J.; Olschewski, H.; Olsson, K.M.; Peacock, A.J.; Pepke-Zaba, J.; Provencher, S.; et al. Pulmonary hypertension in chronic lung disease and hypoxia. Eur. Respir. J. 2019, 53, 1801914. [CrossRef]

40. Jansa, P.; Jarkovsky, J.; Al-Hiti, H.; Popelova, J.; Ambroz, D.; Zatocil, T.; Votavova, R.; Polacek, P.; Maresova, J.; Aschermann, M.; et al. Epidemiology and long-term survival of pulmonary arterial hypertension in the Czech Republic: A retrospective analysis of a nationwide registry. BMC Pulm. Med. 2014, 14, 45. [CrossRef]

41. Skride, A.; Sablinskis, K.; Lejnieks, A.; Rudzitis, A.; Lang, I. Characteristics and survival data from Latvian pulmonary hypertension registry: Comparison of prospective pulmonary hypertension registries in Europe. Pulm. Circ. 2018, 8, 2045894018780521. [CrossRef] [PubMed]

42. Weatherald, J.; Reis, A.; Sitbon, O.; Humbert, M. Pulmonary arterial hypertension registries: Past, present and into the future. Eur. Respir. Rev. 2019, 28, 190128. [CrossRef] [PubMed]

(C) 2020 by the authors. Licensee MDPI, Basel, Switzerland. This article is an open access article distributed under the terms and conditions of the Creative Commons Attribution (CC BY) license (http://creativecommons.org/licenses/by/4.0/). 